\title{
TRANSPORT
}

DOI https://doi.org/10.30525/978-9934-26-109-1-28

\section{ПАРАМЕТРИЗАЦІЯ ПРОЦЕСУ ПРОЕКТУВАННЯ ДЕТАЛЕЙ ДВИГУНА АВТОМОБІЛЯ З ВИКОРИСТАННЯМ САПР SOLIDWORKS}

\author{
Йовченко А. В. \\ старший викладач \\ Черкаський держсвний технологічний університет \\ м. Черкаси, Україна
}

\begin{abstract}
Параметричне моделювання (параметризація) - моделювання (проектування) 3 використанням параметрів елементів моделі i співвідношень між цими параметрами. 3 використанням параметризації можливо за короткий час змоделювати за допомогою геометричних співвідношень або зміни параметрів різні конструктивні схеми та уникнути принципових помилок.
\end{abstract}

При параметризованому проектуванні створюється математична модель об'єктів з параметрами, при зміні яких відбуваються зміни конфігурацій деталей, взаємні переміщення деталей в збірці.

Параметризація дозволяє безліч разів використовувати розроблену модель та значно скорочує час на проектування деталей механізму, підготовку креслень та іншої супутньої проектної документації.

Основним інструментом параметризації SolidWorks 2019 є блок «equations» в дереві конструювання функцій Manager. Параметризувати зборку можна з дуже високим ступенем деталізації.

При параметризації деталей автомобіля на прикладі кривошипношатунного механізму (КШМ) в САПР SolidWorks використовуються операції створення об'ємних тіл, зберігається ідентичний порядок основних операцій САПР. Перед параметризацією необхідно визначити основні конструктивні співвідношення розмірів КШМ [1]. Наприклад, величину верхньої частини поршня $h_{l}$ вибирають, виходячи із забезпечення однакового тиску опорної поверхні поршня по висоті циліндра й міцності бобишок, ослаблених отворами для пропуску оливи. Висоту головки поршня $h_{\Gamma}$ встановлюють виходячи із нормального 


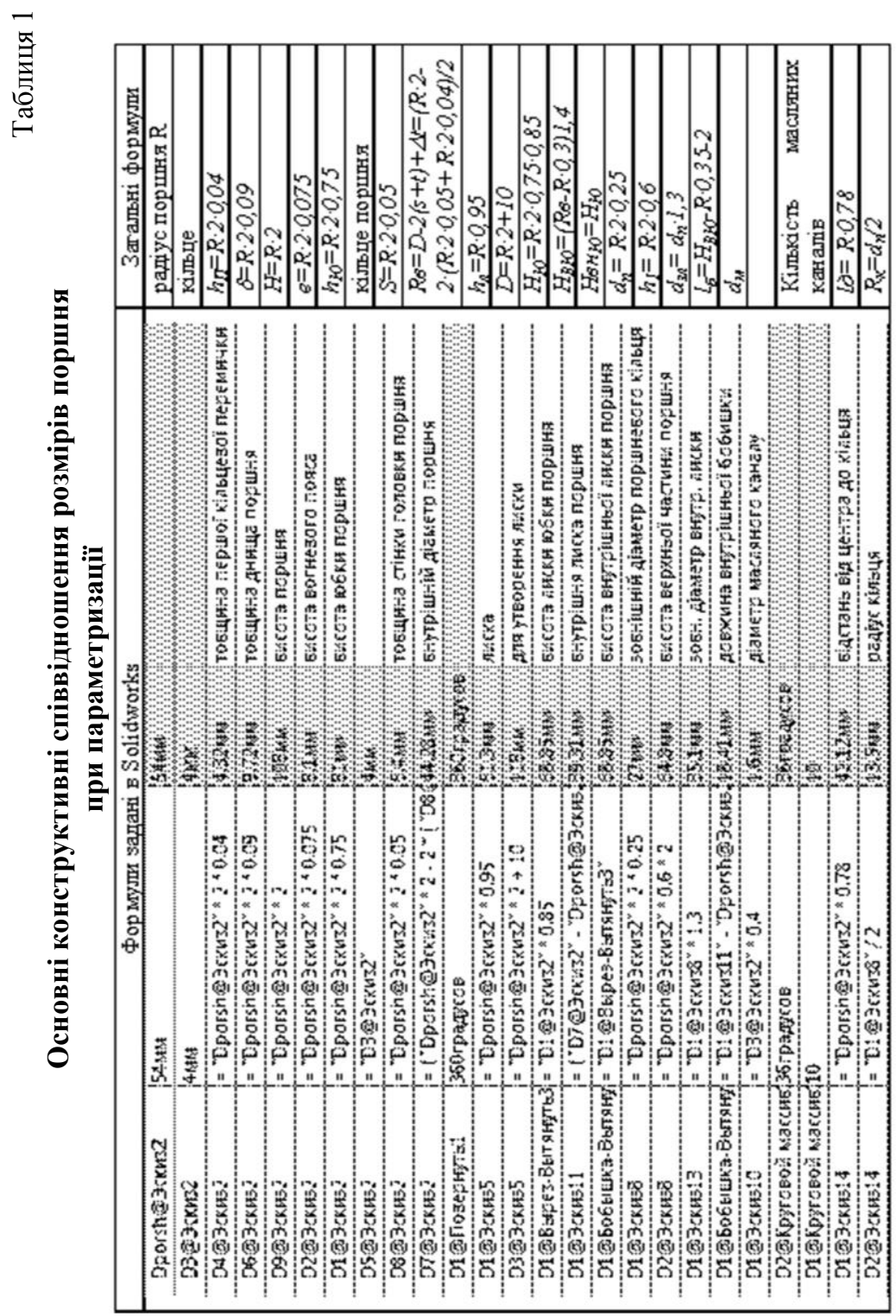


температурного режиму iї елементів - товщини дна поршня й розташування кілець. Висота юбки $h_{ю}$ визначається величиною необхідного теплового зазору між юбкою поршня й циліндром.

Перед параметризацією визначається основний розмір, відносно якого створюється параметризована модель, основні конструктивні співвідношення розмірів деталей КШМ (табл. 1): поршня, кільця, поршневого пальця, шатунної групи, поршневої головки, кривошипної головки, стержня шатуна, колінчатого валу.

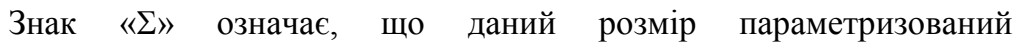
3 використанням основного розміру - діаметра поршня $D$ (рис. 1-2) $[2 ; 3]$.

Для параметризації поршневого пальця, шатуна та інших деталей КШМ виконуємо моделювання даних деталей в SolidWorks. Параметризація виконується під час зборки КШМ (рис. 2).
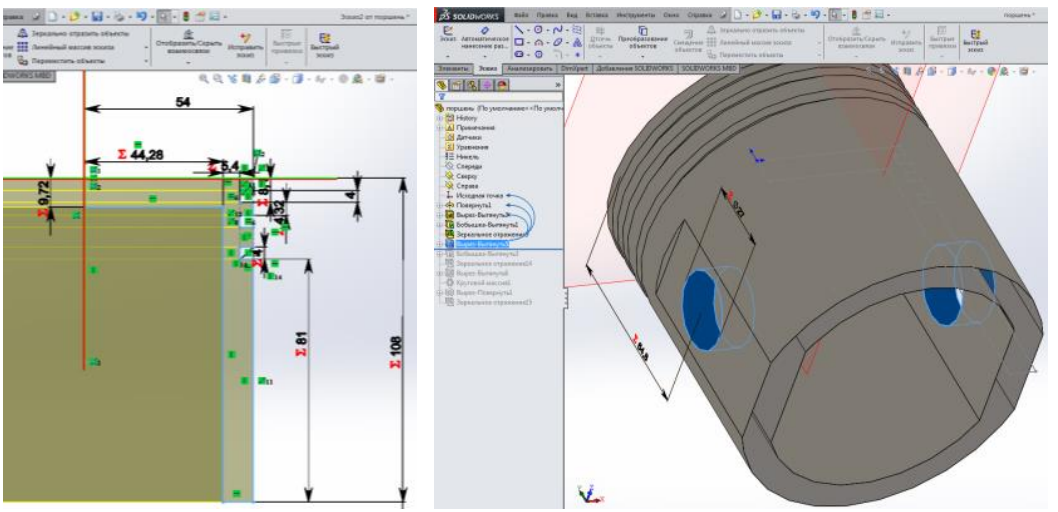

Рис. 1. -Ескіз операції «обертання», «вирізати» та «дзеркальне відображення» в Solidworks 3 параметризованими розмірами поршня та для створення внутрішнього отвору поршня під поршневий палець

Основні рівняння, що використовувались під час параметризації шатуна вказані в табл. 2. Подальша параметризація КШМ відбувається за подібною методикою.

Згідно із статистичними даними, на зміну параметрів повністю параметризованої 3D-моделі йде менше 1 хв. При цьому перебудовування відбувається в автоматичному режимі. 
Technical sciences: the analysis of trends and development prospects

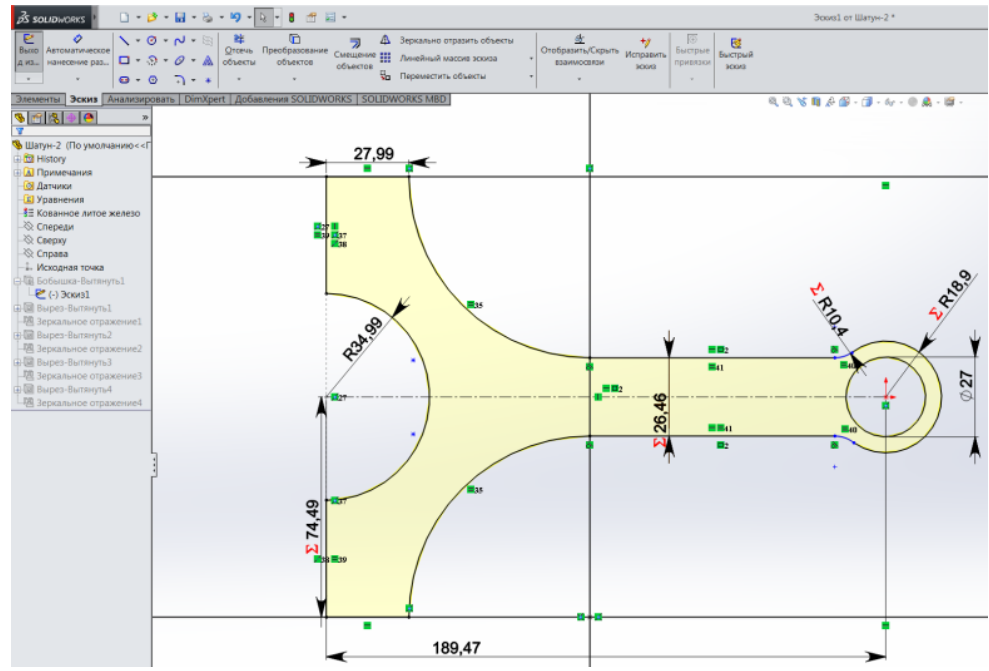

Рис. 2. Ескіз операції «витягування» в Solidworks для отримання деталі «Шатун»

Таблиця 2

Основні конструктивні співвідношення розмірів елементів при параметризації

\begin{tabular}{|c|c|c|c|c|}
\hline D1@Эохиз1 & $27 u M$ & $27 \mathrm{~mm}$ & & dn діаметр поршневого пальц \\
\hline D7@Зсоиз1 & 189.47 мм & 189.47мм & & $L_{ \pm}=\mathrm{R} 0.285$ довжина шатуна \\
\hline D8@300131 & 27.99um & $2799 \mathrm{~mm}$ & & hw ${ }^{\prime}=r_{\mathrm{m}} \cdot 0,8 \mathrm{\text {товщшатпід } 6 0 л т и ~}$ \\
\hline D10@Эоиз1 & $=$ 'D12@Jcovis1' * $1.7+15$ & $74.49 \mathrm{Mm}$ & ширина шатуна & $h u=\operatorname{deu} \cdot 1,7+15$ \\
\hline D12@Jour1 & $34.99 \mathrm{um}$ & $3499 \mathrm{Mm}$ & & $r_{\text {m раұуус шйки }}$ \\
\hline D3@Эосиз1 & $=$ "D1@Jосиз1" * 1.4 *0.5 * 1.4 & $26.46 \mathrm{~mm}$ & товщина стерхня шаууна & $h c=d n \cdot 1,4 \cdot 0,5 \cdot 1,4$ \\
\hline D2@Эосиз1 & $=$ "D1@Эосиз1" * $1.4 / 2$ & 189 мм & 3овнішній даметр поршневої гоповои & $d z=d n 1,4 / 2$ \\
\hline 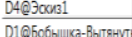 & 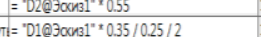 & $\begin{array}{l}10.4 \text { MM } \\
189 \text { MIM }\end{array}$ & $\begin{array}{l}\text { Зєднання порневоі головои шатуна } 3 \text { стерхнем шату } \\
\text { довкона поршневої голови шатуна }\end{array}$ & $d_{3}=d z=0,55$ \\
\hline D2@Бобышшка-Вытянут & $\pi \mathrm{m}=$ "D1@бобышка-ВытянVть1" & 189 мm & 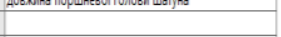 & $l u=\ln \cdot 0,35 / 0,25 / 2$ \\
\hline D1@Jocus2 & $=$ "D3@Jосиз1" - 8 & $18,46 \mathrm{mM}$ & ширина западинии & lus \\
\hline D3@300132 & $={ }^{\prime} \mathrm{D} 1 @ Э а с и 32 " / 3$ & $6.15 \mathrm{Mм}$ & внутішні рафууси западини & $h_{\operatorname{man}}=h_{-}-8$ \\
\hline D6@3unus2 & $=$ "D1@Juxns1" + 4 & $31 \mathrm{~nm}$ & відстань від центра поршневого пальця до запаяян & $r_{2 a n}=h_{2 a t} / 3$ \\
\hline D5@300132 & $=$ "D7@Эосиз1" - "D6@Эосиз2" - "D12@Эосиз & 1308.48mu & довжона западуна & $1=d n+4$ \\
\hline D1@Вырез-Bытянты 1 & $=$ = 'D2@бобышка-Вытянить' - 2 & $169 \mathrm{~mm}$ & гмибина западини стерхкен шат)на & $l_{3 e n}=L_{m}-l-1-r_{m}-15$ \\
\hline D1@Вырез-Вытянтт:2 & $={ }^{2} \mathrm{D} 2 @ Э$ осиз $11^{*} \times 0.5$ & $9.45 \mathrm{Mм}$ & товщина стерхня & $h_{2}=\ln -2$ \\
\hline D1@Эсииз & $=$ "D12@3covil' *1.7 & $59.49 \mathrm{~mm}$ & віфстаны мік болтами & внутрішні радіуси западнни \\
\hline D1@Jcou15 & $22 \mathrm{um}$ & $22 \mathrm{~mm}$ & & $l_{6}=r_{11} 1,7$ \\
\hline
\end{tabular}

На рис. 3 зображено отриману параметризовану модель КШМ.

Висновок: в роботі розглянуто основні можливості САПР SolidWorks для параметризації складних механізмів на прикладі КШМ, зокрема операції формування об'ємів, методи роботи 3 ескізами, технології формування складальних одиниць із 
застосуванням інструментів спряжень. Сформовано параметризовану складальну конструкцію КШМ в САПР SolidWorks, яка дозволяє швидко перебудовувати деталі КШМ, виконувати розрахунок даних деталей на міцність із підключеним модулем SolidWorks Simulation.

Уравнения, глобальные переменные и размерь

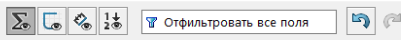

\begin{tabular}{|c|c|c|c|c|c|c|c|c|}
\hline & Имя & & & Значение / Уравнение & Равняется & 宸 & Заметки & \\
\hline & - $\mathbf{р}_{\text {равнения }}$ & омпон & & & & & & \\
\hline & "D2@Эски & @Пале & $2>$.Part" & = "D1@Эскиз8@поршень< 1 >.Part" & $27 \mathrm{Mm}$ & $\square$ & зовнішній діаметр поршневого пал & \\
\hline & "D1@Эски & ఏШат & $21<1>$.Part" & = "D2@Эскиз1@Палец<2>.Part" & $37.5 \mathrm{Mm}$ & $\square$ & зовнішній діаметр поршневого пал & \\
\hline & "D7@Эски & @Шат & $21<1>$,Part" & $=$ ="Dporsh@Экииз2@поршень< $<>$ Part" / 0.285 & $189.47 \mathrm{MM}$ & $\bar{\square}$ & довжина шатуна & \\
\hline & "D12@Эck & 1@Ша & $+-21<1>$.Part" & = "D1@Эскиз1@втулка<4>.Part" & $34.99 \mathrm{Mm}$ & $\square$ & радіус шийки шатуна & \\
\hline & "D8@Эски & @Шат & $21<1>$.Part" & $=$ "D12@Эскиз1@Шатун-21<1>.Part" * 0.8 & $27.99 \mathrm{Mm}$ & $\square$ & товщина шатуна під болти & \\
\hline & "D2@Эски & @криц & шатуна- $1<1>$.Par & $r=$ ="D1@Эскиз1@втулка <4>.Part" & $34.99 \mathrm{Mm}$ & $\square$ & радіус шийки шатуна & \\
\hline & "D1@Эски: & @криц & шатуна- $1<1>$.Par & $r=$ "D10@Эскиз1@Шатун-21<1>.Part" & $74.49 \mathrm{Mm}$ & $\bar{\square}$ & ширина шагуна & \\
\hline & "D4@Эски & @криц & шатуна- $1<1>$.Pan & r= "D8@Эскиз1@Шатун-21<1>.Part" * 0.7 & $19.6 \mathrm{Mm}$ & $\bar{\square}$ & висота кришки шатуна під болт & \\
\hline & "D3@Эски: & @криц & шатуна- $1<1>$.Par & $r=$ "D2@Эскиз1@кришка шатуна-1<1>.Part" * 1.4 & $48.99 \mathrm{Mm}$ & $\square$ & зовнішній радіус кришки шатуна & \\
\hline & "D2@Бобь & ка-Вы & уть1@кришка шат & = "Dporsh@Эскиз2@поршень<1>.Part" * 0.35 & $18.9 \mathrm{~mm}$ & $\square$ & половина товщини шатуна & \\
\hline & "D1@5ooь & ка-Вы & уть1@кришка шат & t= "D2@Бобышка-Вытянуть1@кришка шатуна-1<1>.Part" & $18.9 \mathrm{~mm}$ & $\square$ & половина товщини шатуна & \\
\hline & "D2@6о6ь & ка-Вы & 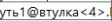 & = "Dporsh@Э๔из2@поршень<1>.Part" ×0.35 & $18.9 \mathrm{Mm}$ & $\bar{\square}$ & половина товщини шатуна & \\
\hline & "D1@Бобь & ка-Вы & 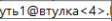 & .= "D2@Бобышка-Вытянуть1@втулка $<4>$ Part" & $18.9 \mathrm{Mm}$ & $\square$ & половина товщини шатуна & \\
\hline & "D2@Эски & Qвтул & $<4>$ Part" & $=$ "Dporsh@Эскиз2@поршень<1>.Part" * 0.6 & 32.4MM & $\square$ & радіус противаги колінчатого валу & \\
\hline & "D1@Бобь & ка-Вы & уть $1 @$ Палец<2>., & = ('D1@Эскиз14@поршень<1>.Part" - "D5@Эскиз14@пор & $80.24 \mathrm{~mm}$ & $\square$ & довжина поршневого пальци & \\
\hline & "Dporsh@: & из2@ & ошень $<1>$.Part" & $=" \mathrm{Dp} "$ & 54мм & $\bar{\square}$ & радіус поршня & \\
\hline & "D1@Эски & @втул & $4>>$.Part" & = "D2@Эскиз1@втулка<4>.Part" + "D2@Эскиз1@втулка<4. & $34.99 \mathrm{Mm}$ & $\bar{\square}$ & радіус шийки шатуна & \\
\hline & "D1@Эски: & @карт & $<1\rangle$.Part" & $=$ "Dp" & 54мM & $\square$ & & \\
\hline & "D3@Эски: & Фкарт & <1>.Part" & $=" D p " / 7.6$ & $7.11 \mathrm{Mm}$ & $\bar{\square}$ & & \\
\hline & "D4@Эски: & @карт & <1>.Part" & $=" \mathrm{Dp} " / 7.6$ & $7.11 \mathrm{Mm}$ & $\square$ & & \\
\hline & "D1@вытя & Tb-Tor & стенный1@картер & $\mathrm{d}=\mathrm{Mp} " / 115.2$ & $3.55 \mathrm{~mm}$ & $\bar{\square}$ & & \\
\hline & "D1@Эски: & @карт & $<1>$.Part" & $=(0.6 * " \mathrm{Dp} " * 2) / 2$ & 32.4MM & $\square$ & & \\
\hline & "D2@Эски: & @карт & $\langle 1\rangle$, Part" & $=" \mathrm{Dp} " * 3$ & $162 \mathrm{MM}$ & $\square$ & & \\
\hline & "D5@Эски: & ఏкарт & <1>.Part" & $=(0.6 * " D p " * 2) / 0.6 * 0.74+(0.6 * " D p " * 2) / 0.6 * 0.2+$ & $125.82 \mathrm{Mm}$ & $\bar{\square}$ & & \\
\hline & "D2@Эскиз & @карт & <1>.Part" & $=$ ="D5@Эскиз4@картер<1>.Part" & $125.82 \mathrm{MM}$ & $\square$ & & \\
\hline & "D7@Эскиз & @карт & <1>.Part" & $=(0.6 * " \mathrm{Dp} " * 2) / 0.6 * 0.74 * 2+(0.6 * " \mathrm{Dp} " * 2) / 0.6 * 0$ & $672.84 \mathrm{Mm}$ & $\square$ & & \\
\hline & "D3@Эскиз & @карт & $<1>$.Part" & = ( 'D7@Эскиз4@картер<1>.Part" - "D5@Эскиз4@картер< & $32.4 \mathrm{~mm}$ & $\square$ & & \\
\hline & "D4@Эскиз & @карт & $<1>$.Part" & = "D3@Эскиз4@картер<1>.Part" & 32.4MM & $\square$ & & \\
\hline & "D6@Эскиз & Фкарт & $<1>$.Part" & $=$ "D3@Эскиз4@картер<1>.Part" & 32.4мm & $\square$ & & \\
\hline & "D1@Эскиз & @колі & $1 / 2>$ Part" & $=" D p "$ & $54 \mathrm{Mm}$ & $\square$ & & \\
\hline & естраивать & $\theta$ & Угловые единицы & $\square_{\text {решения }}^{\text {Автоматический порядок }}$ & & & & \\
\hline$\nabla^{c}$ & $\begin{array}{l}\text { язь с внешним } \\
\text { йлом: }\end{array}$ & & аметризовані дета & аліуравнения кол.txt & ... & $\theta$ & & \\
\hline
\end{tabular}

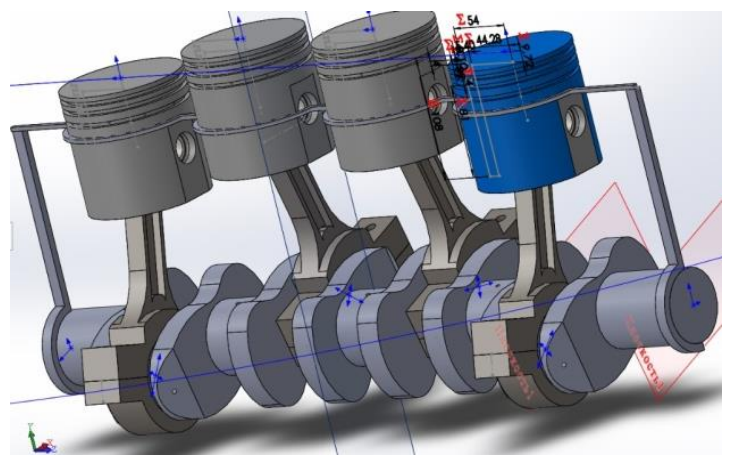

Рис. 3. Параметризована модель КШМ 


\title{
Література:
}

1. А.И. Колчин, В.П. Демидов. Расчет автомобильных и тракторных двигателей. 3-е изд., перераб. и доп. М.: Высш. шк., 2003. 496 с.

2. Алямовский A.A. SolidWorks 2007/2008. Компьютерное моделирование в инженерной практике (+ DVD-ROM): Научное пособие. К.: Інформавтодор, 2008. 62 с.

3. Прохоренко В.П. SolidWorks. Практическое руководство. М.: ООО «Бином-Пресс», 2004 г. 448 с.

DOI https://doi.org/10.30525/978-9934-26-109-1-29

\section{РОЗВ'ЯЗАННЯ ТРАНСПОРТНИХ ЗАДАЧ ЗА ДОПОМОГОЮ ТАБЛИЧНОГО ПРОЦЕСОРА МICROSOFТ OFFICE EXCEL}

\author{
Прокудін Г. С. \\ доктор технічних наук, професор, \\ завідувач кафедри міжнародних перевезень та митного контролю \\ Національний транспортний університет
}

\section{Єрко Я. В.}

аспірант кафедри міжнародних перевезень та митного контролю Національний транспортний університет

\section{Редіч Ю. А.}

аспірант кафедри міжнародних перевезень та митного контролю Наиіональний транспортний університет

$$
\text { м. Київ, Украӥна }
$$

Задача комівояжера - це найбільш відома i знакова модель потокового програмування. Увагу до цієї задачі привертають завдяки: великій кількості практичного значення, що до неї зводяться; зосередження характерних математичних, алгебраїчних та обчислювальних труднощів.

Наявні методи розв'язування сітьових транспортних задач успішно можуть бути застосовані лише в матричній постановці, коли заздалегідь відома матриця транспортних кореспонденцій [1, с. 26]. 